\title{
17 \\ PRIVACY, SECURITY, AND TRANSPARENCY: ICT-Related Ethical Perspectives and Contrasts in Contemporary Firms
}

\author{
Antonino Vaccaro \\ Carnegie Mellon University \\ Pittsburgh, PA U.S.A. \\ and Instituto Superior Técnico \\ Lisbon, Portugal
}

\begin{abstract}
This paper analyzes the ethical perspectives associated with the introduction and use of information and communication technologies in contemporary firms. It presents a three-dimensional ethical model that introduces the transparency concern, and its related impact on the digital divide question, as the new ethical perspective of contemporary business organizations.
\end{abstract}

Keywords Business ethics, information ethics, information and communication technologies

\section{INTRODUCTION}

The impressive development of information and communication technologies (ICT) in recent decades has supported a widespread diffusion of these tools in the social and economic life of developed countries around the world. The pervasive adoption of virtual applications has significantly changed cultural, social, and economic equilibria through a radical modification of social relationships in private, public, and professional dimensions. The aim of the current work is to point out and analyze the ethical perspectives of ICT adoption and use at the firm level in contemporary business organizations. This will be accomplished by reviewing the current literature about the subject by focusing upon varied research fields such as business ethics (e.g., Crane and Matten 2004), information ethics (e.g., Floridi and Sanders 2002), media ethics (e.g., Bettetini and Fumagalli 2002), ethics and technology (Tavani 2004), and computer ethics

Please use the following format when citing this chapter:

Vaccaro, A., 2006, in IFIP International Federation for Information Processing, Volume 208, Social Inclusion: Societal and Organizational Implications for Information Systems, eds. Trauth, E., Howcroft, D., Butler, T., Fitzgerald, B., DeGross, J., (Boston: Springer), pp. 245-258. 
(Johnson 2001), among others.' In this sense, we acknowledge that the state of the art lacks an integrated review of the different perspectives concerning this theme offered by the research of social sciences.

This paper contributes to the literature in several ways. First, it introduces and defines the various forms of transparency as a new, important ethical perspective for contemporary business organizations. To the best of our knowledge, it is the first work that approaches this theme in the context of management of information systems and business ethics disciplines. Moreover, as we will see, internal transparency represents an important ethical concern inside the digital divide discourse. Second, this paper provides an integrated vision of the various ICT-related ethical problems that affect contemporary companies presenting an integrative model based on the review of the literature of a wide group of research fields. Third, useful considerations and implications for practitioners and scholars are provided.

The remainder of the paper is organized as follows. First, some preliminary definitions and considerations to focus our conceptual path are provided. The Rawlsian "veil of ignorance" is introduced, followed by three parts analyzing, respectively, privacy, security, and transparency concerns. The final section provides a brief discussion and a series of related considerations and policy implications.

\section{SOME INTERESTING DEFINITIONS AND PRELIMINARY CONSIDERATIONS}

In recent decades, various authors have emphasized and described the uniqueness of the features and capabilities of ICT (e.g., Moor 1985; Tavani 2004). As a consequence, there has been an over-evaluation of ICT-related ethical problems. Argandoña (2003, p. 7) argued that the ethical neutrality of ICT can be legitimately questioned because "any technology that can be used immorally must be developed with caution." Indeed, he points to the example of a category of ICT tools (i.e., monitoring technologies) that are "more likely to be used for illicit purposes" (p. 7). Following Argandoña's perspective, we analyze a broad definition of ICT in order to determine whether the core categories of uses associated with new virtual technologies can be related to ethical or nonethical purposes.

Information technology (IT) or information and communication technology (ICT) is the technology required for information processing. In particular the

\footnotetext{
'We did not set out to study (1) uses of ICT already recognized as illegal, such as development and diffusion of computer viruses, computer piracy, unauthorized information access, computer fraud, or corporate sabotage, (2) the ethical impact of ICT adoption for social purposes by private or institutional actors, or (3) the different conceptions of ethical uses of ICT in the population of users.
} 
use of electronic computers and computer software to convert, store, protect, process, transmit, and retrieve information from anywhere, anytime. ${ }^{2}$

If we consider human writing, we can verify that its definition and its ultimate objectives are similar to those of ICT because human writing is simply an old, "traditional" form of ICT. To support our observation we will adapt the definition of ICT to human writing.

Human writing is the technology required for information processing. In particular, the use of characters, paper, and ink to convert, store, process, transmit, and retrieve information anywhere, anytime.

Whatever the ethical position of the reader, surely human writing is believed to be ethical. As we have recognized, ICTs represent a wider form of information transmission just as human writing was several millennia ago in relation to previous methods of communication. This consideration assures us that a priori the main uses associated with ICT are similar to traditional writing. Consequently, assuming the ethical neutrality of ICT, our investigation will focus on the uses of these technologies in the specific context of our interest, business organizations.

\section{IDENTIFYING THE ETHICAL QUESTIONS}

Our approach to identifying the ethical questions posed in this work is based on the Rawlsian theory of justice as faimess (Rawls 1971). We have chosen this philosophical theory for various reasons. First, Rawls' ethical model has changed contemporary ethical philosophy (Abbá 1995), supporting a new and effective way to approach the pluralism of contemporary society. Second, the theory of justice as faimess has been applied in diverse practical ethical questions related to egalitarian issues such as feminism cases (e.g., Moller Okin 1989), the defense of homosexual rights (e.g., Dobbs 2004), and specific ICT-related ethical debates such as privacy and employee surveillance (e.g., Introna 2001). Third, as we will see in the following passages, the Rawlsian approach to identifying ethical questions allows a wide applicability and generalization of the insights introduced in the model.

Rawls proposes a public morality developed through a social contract in which all actors are in an "original position." The idea is "to nullify the effects of specific contingencies which put men and women at odds and tempt them to exploit social and natural circumstances to their own advantage" (Rawls 1971, p. 136). Under the veil of ignorance, the condition in which no one knows in which social position they will live, everyone would agree to some basic rules of society. Moreover, Rawls assumes that agents involved in the development of public morality are rational and their objective

${ }^{2}$ The definition is from the wikipedia encyclopedia, The choice of this reference for our definition is not fortuitous. We analyzed more than 50 definitions in the MIS literature, in dictionaries, etc. It is consistent and comprehensive of all references analyzed. 
is social cooperation between equals with the intention of reciprocal advantage. ${ }^{3}$ Therefore, our basis for identifying and proposing the ethical considerations will be the question: Under the veil of ignorance, will a rational actor agree with the development of this kind of use of ICT tools in firms' activities?

In relation to the introduction of ICT into our society, the main ethical problems recognized in the various literatures relate to a wide set of concerns, such as privacy (e.g.,Introna 1996; Ottensmeyer and Heroux 1991), intellectual property (e.g., Winter et al. 2004), workplace conditions (e.g., Brown and Duguid 2000; Castells 1996; Perrolle 1998), security of individuals (e.g., Fung and Lee 1999), and the digital divide (Tavani 2004). We recognize within this heterogeneous and wide range that the problems affecting firms' activities can be described along two main dimensions: the first is privacy, the second security and safety of individuals. In this work we propose another dimension that, to the best of our knowledge, has not been approached in detail in the literature: firms' transparency. As firms' activities are both internal and external, we will consider for each of the introduced dimensions two levels of ethical investigation and analysis, which we will define respectively as internal and external levels. We therefore propose a three-dimensional (privacy, security, and transparency) and two-level (internal and external) model, useful for both scholars and practitioners to frame the main ethical problems arising from the adoption and use of ICT for firms' activities $^{4}$ (see Figure 1). The model presents an ethical question for each couple dimension/level. The assumption that actors involved in the ethical discourse have heterogeneous ethical beliefs suggests proposing appropriate ethical questions, rather than propositions, in order to allow a wide usability and generalization of the offered insights. ${ }^{5}$ Each of these questions should be taken as representative of inquiries into a wider series of specific ethical issues that affect the management of information systems in the selected dimension and level of analysis.

\section{THE FIRST DIMENSION: MULTIPLE, VARIEGATED FACES OF THE PRIVACY}

In the last decade, problems related to the respect of personal privacy have widely interested intellectuals, practitioners in every managerial field, and institutions at every level. As Tavani (2004, p. 42) pointed out, "of all the ethical issues associated with the use of cybertechnology, perhaps none has received more media attention than the concern about the loss of personal privacy in the Internet era."

${ }^{3}$ These are perfectly reasonable assumptions with which to approach our ethical problems at the firm level: social cooperation in order to allow reciprocal advantage and rationality of agents are necessary starting points for every business organization.

${ }^{4}$ The model does not cover intellectual property concerns because we did not find in the literature indications regarding the impact of these issues at the firm level. Moreover, we expect that intellectual property problems are or should be adequately regulated by the national norms under which each company operates.

${ }^{5}$ Other referred works in the business ethics field (e.g., Nash 2003) have adopted this editorial and methodological strategy. 


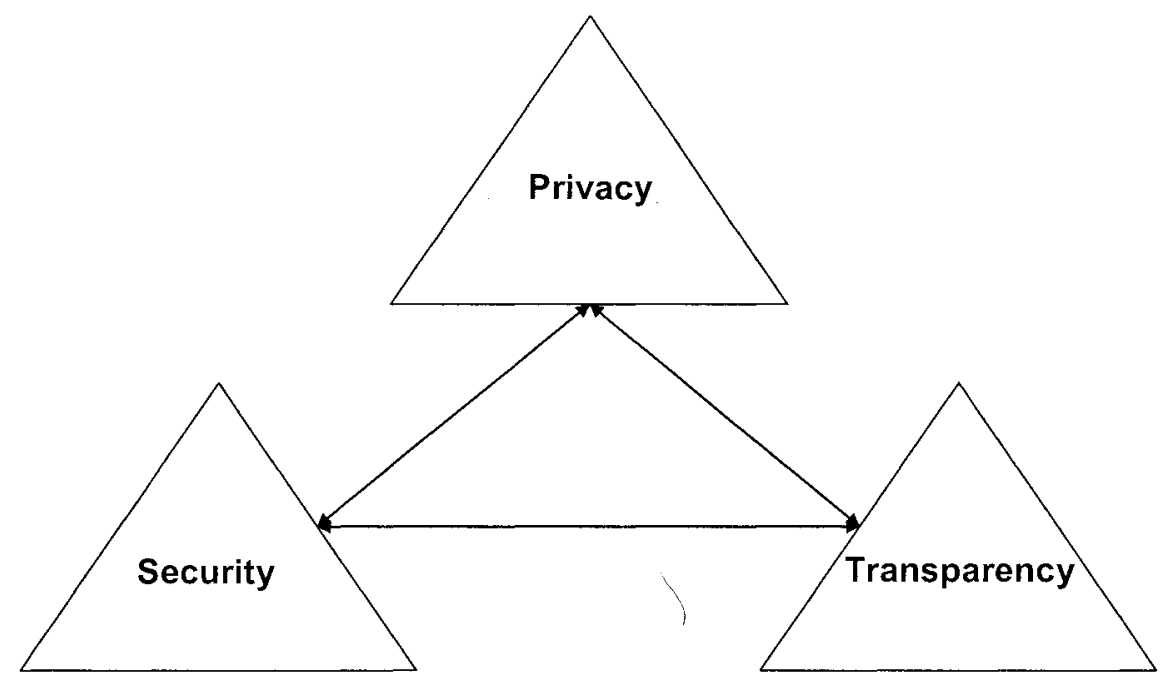

Figure 1. The Three Dimensions of the Model

It is a shared belief that ICT have created a surveillance society in which the issue of individual privacy is no longer space and time bound (Barlow 1991; Introna 1996, 2002; Lyon 1994) and affects each individual at different levels. There is in fact irrefutable evidence that the computer as a work tool enables new forms of surveillance (Ottensmeyer and Heroux 1991) and that the advent of electronic commerce brings with it a host of ethical issues surrounding customer privacy (Sarathy and Robertson 2003). We will refer to privacy as the concept of a person's right to control information about him/herself and the situations over which such a right may be legitimately extended ${ }^{6}$ (Cranford 1998).

Analysis of the literature confirms that two actors have been mainly affected by the introduction and diffusion of ICT tools inside firms' organizations: employees and customers. For example, Spinello (2004) provided a series of case studies showing that the possibilities arising from the use of ICT caused serious privacy issues in relationships with both customers and employees. Thus, privacy concerns affect ICT use in contemporary companies at two different levels: the external, in the relationships with customers, and internal, in management's interaction with employees.

${ }^{6}$ This definition is consistent with others in the literature such Mason (1986), Shaw, (2003), and the Oxford and Webster Dictionary. While the term privacy was first used in English in about 1450 , its importance was recognized for the first time in an official document of the $19^{\text {th }}$ century. In a ruling dated 1888, an American judge, Thomas Cooley, defined privacy as the right "to be let alone." Two years later, Warren and Brandeis (1890) recognized "recent inventions and business methods," like "instantaneous photographs and newspaper enterprise," as causes of new forms of privacy violation. 


\subsection{Privacy in Internal Relationships}

In the internal dimension, the privacy of the workforce is mainly violated due to the ability to monitor the activities of employees continuously and without limits. Managers can in fact observe in real time what exactly an employee is doing through the use of a multitude of basic and inexpensive computer-based monitoring products that allow them to track Web use, observe downloaded files, discover how much time employees spend on various Web sites, etc. (Hartman 2001). Marx (1999) suggests that ICTs have enabled contemporary companies to develop an organizational behavior similar to that of the ideal prison proposed by the philosopher Jeremy Bentham in 1791 : a building of polygonal structure with a central tower that offers a full view of rows of glass walled cells, where the mirrors around the tower made it possible for the guards to look into each cell while staying invisible to prisoners.

The development and use of electronic tools in contemporary firms has supported a change in the principal-agent relationship. It seems evident that ICTs have increased the principal's control over the activities of the agent. In this new situation the flow of information favors the principal, who has gained multiple ways to control the agent. ${ }^{\text {? }}$

On the other hand, in every work relationship there is a reasonable limit to the control exercised by the principal beyond whom the agent can invoke a natural respect for his/her physical privacy. Many workers in fact resent such monitoring (Marx 1992), feeling violated and powerless (Marx and Sherizen 1986).

A balance between employers' interest in managing the workplace and employees' privacy interests should be reached in every business organization (Hartman 2001). Every person under the veil of ignorance would agree on the need to set a limit on the control of his/her work activities exercised by the principal. Thus, our first question is: Under the veil of ignorance, what could be the ethical limit related to the use of ICTs in order to control employees' activities during working hours?

\subsection{Privacy in the External Relationships}

More rapidly available and more accurate information does not affect only the principal-agent relationship within firms but also has raised new questions related to the information privacy ${ }^{8}$ of all actors external to the firm's organization and customers in particular. ${ }^{9}$ Indeed, contemporary firms have the opportunity to collect and analyze

${ }^{7} \mathrm{~A}$ reduction of asymmetric information in the principal-agent relationship does not per se offer particular new ethical questions. While economic theory has resolved the principal-agent relationship through adequate incentive mechanisms, a reduction of the asymmetry per se should reduce the possibility of morally hazardous behaviors.

${ }^{8}$ Information privacy is the right to determine how, when, and to what extent private data about us is released to others (Simms 1994).

${ }^{9}$ The problem of information privacy has a limited impact at the internal level and in particular in the employee-employer relationship. The introduction of ICTs has in fact only improved the effectiveness of the acquisition and storage of information that was already available in the past. A different scenario is instead offered by the use of ICT in external relationships due to the multiple different possibilities to acquire new and more detailed items of information. 
customers' personal data, with an accuracy and precision that necessitate serious reflection on the limits of these practices. For example, everyone who connects to a company Web site can easily be identified through the IP number of the PC or through Internet cookies; the private and personal information that we submit to be admitted to fidelity firms' programs can be processed for different uses from those officially declared, etc. The lack of a unique international regulation enhances this problem, because customers can not know the national laws of Web site they would visit. Moreover, as Smith and Hasnas (1999) have demonstrated, in addition to the various points of view of institutional and governmental actors, different business ethics theories can support contrasting solutions regarding the use of personal data. Under the veil of ignorance everyone would agree on the need to define a limit regarding the use of his/her personal information by a company or other kinds of institutions. Thus, our second question is: Under the veil of ignorance, what could be the ethical limit related to the use of ICTs in order to collect and exploit customers' personal (private) data?

\section{THE SECOND DIMENSION: SAFETY AND SECURITY OF INDIVIDUALS}

The introduction and diffusion of ICTs have raised ethical questions related to safety and security of individuals both inside and outside the firm. At the internal level, firms' working styles have been transformed by the advent of personal computers and electronic networks with a consequent request of attention to the respect for working conditions. At the external level, firms have started to replace the traditional market, understood as a physical place to interact economically, with virtual markets, in which all kinds of relationships are mediated through ICT. The loss of physical, personal contact has consequently enhanced the ethical perspectives and problems related to the security of individuals engaged in ICT-enabled business activities.

\subsection{Security of Individuals Within the Firm: Acceptable Work Conditions}

Employees' security has represented an ethical concern of business organizations since their constitution. Although the image of exhausted factory workers is far from our perception of contemporary firms, there is still a need to confirm if work environments respect human dignity. The shift, in many sectors of human engagement from physical to mental processes does not a priori guarantee better conditions for the workforce. The automation of administrative procedures can lead to stressful conditions for office employees that have to face a continuous, interminable flow of activities (Perrolle 1998, p. 104). The old requirement for acceptable work conditions reappears in the important themes of contemporary management practice and theory and, in particular, as pointed by Brown and Duguid (2000), in the context of the wide reengineering processes caused by the introduction of new virtual technologies inside business organizations. Under the veil of ignorance, everyone would in fact agree on 
the need to define rules and guidelines regarding the requirements necessary to guarantee decent work environments. Who would risk being allocated to an uncomfortable, unpleasant work position? Thus, our third question is: Under the veil of ignorance, what could be the requirements related to the use of ICTs that guarantee decent working environments for every employee?

\subsection{Security of Individuals Outside the Boundaries of the Firm}

The open, interconnected, and unregulated global nature of the Internet has heightened concerns about the security of economic activities enabled by ICT (Fung and Lee 1999). The market, in the sense of a physical place to meet people and to develop economic exchanges, has been in fact replaced in many situations by virtual e-commerce. This change has led to the loss of many control mechanisms that had matured in traditional markets. The extent of new virtual markets, the lack of personal contact, and the lack of a single international legal system have enhanced the importance of security in Internet-based economic transactions.

Firms have replaced traditional markets in two ways. The first is by creating a virtual shop in which a customer can find and buy goods electronically in a transaction that involves only the customer and the company. The second is the creation of a "marketplace" in which buyers and sellers can virtually meet their counterparts and carry out economic transactions. In the first situation, the current technology provides all the conditions necessary to guarantee customers' security. An honest company in fact has all the technological tools to provide detailed information on the goods sold and the conditions of the purchase. The real security of a virtual transaction itself can be guaranteed with adequate encryption, digital signatures, and third party authentication; such methods have been addressed in detail in the trade and computer science literature ((Bhimani 1996; Varadharajan et al. 1997) and adequately implemented in the real market through the collaboration of financial and ICT leaders (Shapiro and Varian 2000).

At the same time, the diffusion of marketplaces suggests ethical questions related to the rules of exchange governing transactions between external actors. As a single firm has the opportunity to create a virtual place in which it can conduct economic activities, all the rules in this area are created and controlled by the firm itself. In other words, the transactions of different actors extraneous to the company are regulated through the marketplace by a firm that imposes certain rules rather than others. In this context the firm acts as a mediator but has a limited set of data on the actors of the transaction and the object of the transaction. The marketplace is consequently a virtual area in which there is a situation of asymmetric information between the actors involved in the transaction and in which the rules are written by a company. The fourth question that we propose is, therefore: Under the veil of ignorance, what are the rules governing transactions that should be imposed by firms in order to guarantee customers' security in the e-marketplace? 


\section{A NEW DIMENSION: CORPORATE TRANSPARENCY}

The importance of transparency and its impact on market efficiency has been widely analyzed in the micro-finance and economics fields (e.g., Bias 1993; Fleming and Remolona 1999; Ho and Hans 1983) but it has not been closely examined at the firm level. In the following passages we will distinguish between external and internal transparency. The former is defined as the degree of completeness of information, regarding its own business activities, provided by each company to the market. The latter is defined as the degree of virtual connectivity (i.e., availability to access through ICT tools) of the workforce to the external environment.

\subsection{External Transparency as the New Ethical Imperative}

The advent and spread of Internet technology has reduced the distance between firms and a part of developed society. Indeed, firms have the option to disseminate a well controlled set of information through their Web sites. The consequent ethical question is related to the degree of transparency companies should adopt in their new virtual relationships with society. In an ideal society, under the veil of ignorance, everyone would be able to obtain detailed information about the firm's activities, under the guarantee of not using it for commercial or personal benefit, anyone should be able to obtain all information regarding the firm's activities. In real life we can find an already existing similar condition: an increasing number of restaurants have created transparent kitchens that can be checked by customers. While it is not easy to copy the art of chefs through a brief view, these restaurants have decided to increase their customers' knowledge of their internal operations. Moreover, protests organized by consumer associations against multinational companies whose activities are deemed unethical clearly express the real and growing interest in the way business activities are conducted.

Companies around the world have already opened up their information systems to important suppliers and customers to improve their operational effectiveness, reducing costs and lead times. On the other hand, it could be argued that extensive and detailed information on internal activities could be used by competitors to threaten a firm's market position.

While a firm has the right to preserve its business position, it is possible to argue that the degree of transparency of firms' activities could be increased to comply with the request of more detailed information expressed, around the world, by customers. Thus our fifth ethical question will be: Under the veil of ignorance, what could be the expected level of a firm's transparency through ICT in its relationships with the external environment?

\subsection{Internal Transparency: A Social Inclusion Perspective}

Today, employees' ability to access the external environment during working hours is greater than it was two decades ago: the Internet provides a wide range of oppor- 
tunities such as the browsing of Web sites, e-mail, and chat programs (e.g., Windows Messenger). As pointed out in the literature (e.g., Capurro 2000), while in the past the exchange of important information was based on vertical dimensions (top-down relationships along the social or organization structure), the introduction of ICT has supported multidirectional (i.e., both horizontal and vertical) interactive communications. In the firm context, this means that each employee can obtain all kinds of information from a wider range of actors and sources both inside and outside the company's boundaries.

On the other hand, the frequent attempts by employees around the world to use firms' PCs for personal use or for illicit purposes, such as downloading pornography, have resulted in the spread of various forms of limitations on employees' use of ICT tools in their contact with the external environment. While the promise of Internet technology was the creation of a single, global, open network, reducing the multiple externalities of information transactions, a common practice of companies, is in direct opposition to this trend because it limits employees' access and external connections. Indeed, Castells (1996) has proposed a classification of employees based on their level of interconnection with other individuals through ICT tools, in particular the networkers, who are able to establish relationships without constraint, the networked, those individuals that are connected to the Net but are constrained in their communications, and finally the switched-off, who are not linked to the Net.

Assuming that it is reasonable to prevent the use of a company's information systems for personal purposes unrelated to the firm's business activities during working hours, there is neither a managerial nor an ethical basis for limiting employees' interactions with the external environment. The Internet connections available inside the firm can be, in many cases, the sole opportunity for employees to have access to the Web. Contemporary firms consequently have the opportunity to reduce the digital divide exclusion allowing their workforce to use the Internet connection in specific and controlled circumstances. For example, the Banca d'Italia, the Italian central bank, allows employees to use, during lunch break and outside working hours, special PC locations for Web navigation and personal e-mail (Vaccaro and Madsen 2006). Moreover, other solutions can be found in relation to specific organizational and business circumstances. Indeed, with adequate and well-defined controls, there are neither ethical nor technological reasons to forbid employees to use firms' Internet connections for personal reasons outside working hours.

Under the veil of ignorance, everyone would agree on the need to develop norms and guidelines governing the transparency of companies' information systems for employees in their relationship with the external environment in order to guarantee the social inclusion of workforces.

Thus, our last question is: Under the veil of ignorance, what could be the ethical limit to the reduction of ICT transparency (possibility of information exchange) between workers and the external environment in order to allow the social inclusion of the workforce?

\section{DISCUSSION AND CONCLUSION}

The path we have followed has revealed the presence of a wide variety of ethical needs and demands related to the use of ICTs in contemporary business organizations. 
Some of these themes are well-known, old problems, such as those related to acceptable working conditions, which have been transposed to the technological world. Others, such as privacy concerns, are old ethical issues that have been enhanced in degree and complexity by the potential of ICTs. Finally, there are other ethical issues, like transparency, that are related both to the increased ethical attention of contemporary society to business activities and to the social modification caused by the diffusion of ICTs. In this new scenario, the transparency dimension is very important because it refers both to the customer's increasing need to be more conscious of firms' business practices and to the digital social inclusion of employees. In particular, this last concern represents a condicio sine qua non, a preliminary necessary step, that business organizations should adequately understand and resolve in the development of their strategy and practices.

It is undeniable that the different ethical dimensions analyzed above can be shown to be, in various organizational circumstances and in relation to different individual ethical beliefs, in a trade-off situation. Security and privacy, for example, can be conflicting requirements in the management of external relationships. How in fact is it possible to guarantee security and privacy at the same time in a marketplace? What is the ethical limit that distinguishes right from wrong in the acquisition and use of personal data in order to protect the security of individuals?

Analogously, a manager may see conflicts between the requirements for transparency and for security. What is the level of transparency beyond which there is a real risk of endangering employees' safety? Or, what is the level of transparency beyond which the firm's existence itself can be endangered by competitors accidentally becoming able to spy and to copy? Conversely, it is possible to find organizational and environmental conditions in which some problems, which belong to two of the different dimensions introduced, are compatible or synergic. Moreover, the introduction of different religious, cultural, and ethical points of view can only complicate our discourse, leading to the analysis of highly specific and particular problems from which it is difficult or impossible to extrapolate useful insights for scholars and managers.

A final concern is related to the vision of ethical problems not only as static but also as dynamic social processes. From the point of view of the firm, ethical beliefs are in fact highly dynamic processes related to internal and environmental variables. First, as MacIntyre (1998) has pointed out, ethical demands and needs are generally modified in the same community along the temporal dimension. While the temporal horizon proposed by MacIntyre is considerably longer than the average firm's existence, globalization processes and telecommunications have accelerated social change and consequently contemporary firms have to take account of such individual and collective modifications. Second, entry into new markets, in both geographical and sectoral or technological terms, can bring firms to face with new ethical issues. Third, modification of a market segment in the same geographical area and employees' intergenerational shifts can modify stakeholders' ethical requirements.

Thus, there appears to be no way to approach and resolve these problems, due to the complexity, interdependence, and dynamism of the individual, collective, and social variables involved in such processes.

We argue that there is not in fact a single, well-defined recipe for approaching such problems but also that it is possible to define an organizational strategy to face them. The way we propose is based both on clear transparency concerning firms' policies on the use of ICTs and the development of a participatory system in which all actors 
involved in firms' activities are not only well informed but also able to interact with the firm itself in relation to ICT ethical problems. In other words, we propose that problems related to the use of ICT within business corporations can be resolved through appropriate exploitation of the opportunities offered by the electronic and virtual technologies themselves. For example, the creation of an internal committee could enable communication between top management and the whole workforce; the creation of a special page on the firm's Web site could enable the development of open dialogue with customers, suppliers, and society in general.

In a deliberately provocative way, we are proposing to use the potentialities of ICT to develop a dynamic approach to the multiple, varied, and contrasting ethical expectations of society.

This strategy can present various problems due to the lack of guidelines on how each ethical requirement should be weighted in the process of developing the company's ethical position. For example, should the employees' or the customers' expectations be considered more important in the definition of the firm's ICT policies? Or, in the event of opposing points of view between employees and employers, who should be considered the more important? The answers to such questions are based on the unique features that characterize each firm, on its history, strategic objectives, environmental and cultural variables, and are beyond the scope of this work.

On the other hand, only the combination of an open participatory system and of clear transparent policies can guarantee that firms take into account not only the different ethical expectations of individuals and groups but also the continuous modifications within society and along the temporal dimension. Thus, instead of approaching ethical problems through the development of a rigid set of norms, contemporary firms have the possibility to explore the various dynamic ethical trajectories of their stakeholders and to modify their position accordingly.

The first step of this long and difficult process requires the real digital inclusion of all stakeholders. In relation to this concern, contemporary business organizations can and should provide a real contribution to the society, looking first at their internal organizations and guaranteeing to all employees the possibility to exploit the great opportunities offered by new virtual technologies, with the hope that ICT will became a tool of integration and not another cause of social inequality.

\section{Acknowledgments}

The author is grateful to João César das Neves for the generous support he provided during the development of the paper.

\section{References}

Abbà, A. Quale Impostazione per La Filosofia Morale?, Rome: LAS, 1996. Argandoña, A. "The New Economy: Ethical Issues," Journal of Business Ethics (44), 2003, pp. 3-22.

Barlow, J. P. "Electronic Frontier: Private Life in Cyberspace," Communications of the ACM (34:8), 1991, pp. 23-25.

Bettetini, G. , and Fumagalli, A. Quel Che Resta Dei Media, Rome: Franco Angeli, 2002. 
Bias, B. "Price Formation and Equilibrium Liquidity in Fragmented and Centralized Markets," Journal of Finance (48:1), 1993, pp. 157-185.

Bhimani, A. "Securing the Commercial Internet," Communications of the ACM(39:6), 1996, pp. 29-35.

Brown, J. S., and Duguid, P. The Social Life of Information, Boston: Harvard Business School Press, 2000.

Capurro, R. "Hermeneutics and the Phenomenon of Information," in C. Mitcham (ed.), Metaphysics, Epistemology, and Technology. Research in Philosophy and Technology (Volume 19), Amsterdam: Elsevier, 2000, pp. 79-85.

Cooley, T. A Treatise on the Law of Torts ( $2^{\mathrm{nd}} \mathrm{ed}$.), Chicago: Callaghan, 1888.

Castells, M. The Rise of the Network Society, Oxford, England: Blackwell Publishers, 1986.

Crane, A., and Matten, D. Business Ethics, Oxford, England: Oxford University Press, 2004.

Cranford, M. "Drug Testing and the Right to Privacy: Arguing the Ethics of Workplace Drug Testing," Journal of Business Ethics (17:16), 1998, pp. 1805-1815.

Dobbs, R. R. "Application of a Justice as Fairness Perspective to Laws Banning Same Sex Marriage," Californian Journal of Health Promotion (2), 2004, pp. 15-23.

Fleming, M., and Remolona, E. "Price Formation and Liquidity in the U.S. Treasury Market: The Response of Public Information," Journal of Finance (54:5), 1999, pp. 1901-1915.

Floridi, L.., and Sanders, J. W. "Mapping the Foundationalist Debate in Computer Ethics," Ethics in Information Technology (4), 2002, pp. 1-9.

Fung, R. K., and Lee, M. K. "EC-Trust (Trust in Electronic Commerce): Exploring the Antencedent Factors," in W. D. Haseman and D. L. Nazareth (edsI), Proceedings of the Fifth Americas Conference of Information Systems, Milwaukee, WI, August 13-15, 1999, pp. 517-519.

Hartman, L. Technology and Ethics: Privacy in the Workplace," Business and Society Review (106:1), 2001, pp. 1-27.

Ho, T., and Hans, S. "The Dynamics of Dealer Markets under Competition," Journal of Finance (38:4), 1983, pp. 1053-1074.

Introna, L. D. "The (Im)possibility of Ethics in the Information Age," Information and Organization (12:2), 2002, pp. $71-84$.

Introna, L. D. "Privacy and the Computer: Why We Need Privacy in the Information Society," paper presented at ETHICOMP96, Pontificial University of Salamanca, Madrid, Spain, November 6-8, 1996.

Introna, L. D. "Workplace Surveillance, Privacy, and Distributive Justice," in R. A, Spinello and H. T. Tavani (eds.), Readings in Cyberethics, Sudbury, MA: Joines and Bartlett Publishers, 2001, pp. 418-429.

Johnson D. G. Computer Ethics ( $3^{\text {rd }}$ ed.), Upper Saddle River, NJ: Prentice Hall, 2001.

Lyon, D. The Electronic Eye, London: Polity Press, 1994.

Macintyre, A. A Short History of Ethics, Notre Dame, IN: University of Notre Dame Press, 1998.

Marx, G. T. "Let's Eavesdrop on Managers," Computerworld (26:16), 1992, p. 29.

Marx, G. T. "Measuring Everything that Moves: The New Surveillance at Work," in I. Simpson and R. Simpson (eds.), The Workplace and Deviance, Greenwich, CT: JAI, 1999.

Marx, G. T. , and Sherizen, S. "Monitoring on the Job: How to Protect Privacy as Well as Property," Technology Review (89), November-December 1986, pp. 63-72.

Mason, R. O. "Four Ethical Issues of the Information Age," MIS Quarterly (10:1), 1986, pp. 512.

Moor, J. H. "What Is Computer Ethics?," Metaphilosophy (16:4), 1985, pp. 266-275.

Moller Okin, S. Justice, Gender and the Family, New York: Basic Books Inc., 1989.

Nash, L. "Ethics Without Sermon," in Harvard Business Review on Corporate Ethics, Boston: Harvard Business School Press, 2003. 
Ottensmeyer, E. J. , and Heroux, M. A. "Ethics, Public Policy and Managing Advanced Technologies: The Case of Electronic Surveillance,"Journal of Business Ethics (10), 1991, pp. 519-526.

Perrolle, J. Computers and Social Change: Information, Property, and Power (Web Edition), Belmont, CA: Wadsworth Publishing Company, 1998.

Rawls, J. A Theory of Justice, Boston: Belknap Press, 1971.

Sarathy, R., and Robertson, C. J. "Strategic and Ethical Considerations in Managing Digital Privacy," Journal of Business Ethics (46:1), 2003, pp. 111-126.

Shapiro C., and Varian, H. R. Information Rules: A Strategic Guide to the Network Economy, Boston: Harvard Business School Press, 2000.

Shaw, I. F. "Ethics in Qualitative Research and Evaluation," Journal of Social Work (3:1), 2003, pp. 9-29.

Simms, M. "Defining Privacy in Employee Health Screening Cases: Ethical Ramifications Concerning the Employee/Employer Relationship,"Journal of Business Ethics (13:1), 1994, pp. 315-325.

Smith, H. J., and Hasnas, J. "Ethics and Information Systems: the Corporate Domain," MIS Quarterly (23:1), 1999, pp. 109-127.

Spinello, R. Case Studies in Information Technology Ethics ( $2^{\text {nd }}$ ed.), Upper Saddle River, NJ: Prentice-Hall, 2004.

Tavani, H. T. Ethics and Technology, Ethical Issues in an Age of Information and Communication Technology, New York: John Wiley \& Sons, Inc., 2004.

Vaccaro, A., and Madsen, P. "Firm Information Transparency: Ethical Questions in the Information Age," Working Paper, Carnegie Mellon University, 2006.

Varadharajan, V., Pieprzyk, J., and Mu, Y. "Information Security and Privacy," in Proceedings of the Second Australian Conference, Sydney, Australia, July 7-9, 1997.

Warren, S., and Brandeis, L. "The Right to Privacy," Harvard Law Review (4:5), 1890, pp. 193196.

Winter, S. J. , Stylianou A. C., and Giacalone R. A. "Individual Differences in the Acceptability of Unethical Information Technology Practices: The Case of Machiavellianism and Ethical Ideology," Journal of Business Ethics (54:3), 2004, pp. 275-296.

\section{About the Author}

Antonino Vaccaro is currently a visiting research scholar at Carnegie Mellon University and an assistant researcher at the $\mathrm{N}+$ Center for Innovation, Technology, and Policy Research of Lisbon. He is also collaborating with the Catholic University of Lisbon for the creation of the first Portuguese center of business ethics and social responsibility. Antonino can be reached at vaccaro@andrew.cmu.edu. 